\title{
An experimental test of flexible combinatorial spectrum auction formats
}

\author{
Brunner, Christoph ; Goeree, Jacob K ; Holt, Charles A ; Ledyard, John O
}

\begin{abstract}
This paper reports laboratory experiments that evaluate the performance of a flexible packagebidding format developed by the FCC, in comparison with other combinatorial formats. In general, the interest of policy makers in combinatorial auctions is justified by the laboratory data; when value complementarities are present, package bidding yields improved performance. We find clear differences among the combinatorial auction formats, however, both in terms of efficiency and seller revenue. Notably, the combinatorial clock provides the highest revenue. The FCC's flexible package bidding format performed worse than the alternatives, which is one of the main reasons why it was not implemented.
\end{abstract}

DOI: https://doi.org/10.1257/mic.2.1.39

Posted at the Zurich Open Repository and Archive, University of Zurich ZORA URL: https://doi.org/10.5167/uzh-42536

Journal Article

Originally published at:

Brunner, Christoph; Goeree, Jacob K; Holt, Charles A; Ledyard, John O (2010). An experimental test of flexible combinatorial spectrum auction formats. American Economic Journal: Microeconomics, $2(1): 39-57$.

DOI: https://doi.org/10.1257/mic.2.1.39 


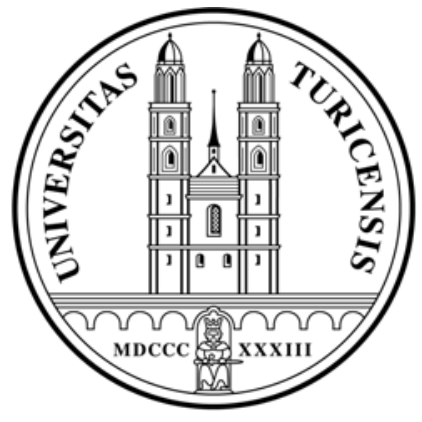

Institute for Empirical Research in Economics

University of Zurich

Working Paper Series

ISSN 1424-0459

Working Paper No. 431

\section{An Experimental Test of Flexible Combinatorial Spectrum Auction Formats}

Christoph Brunner, Jacob K. Goeree, Charles A. Holt, and

John O. Ledyard

September 2009 


\title{
An Experimental Test of Flexible Combinatorial Spectrum Auction Formats
}

\author{
Christoph Brunner, Jacob K. Goeree, Charles A. Holt, and John O. Ledyard'
}

September 1, 2009

\begin{abstract}
This paper reports laboratory experiments that evaluate the performance of a flexible packagebidding format developed by the FCC, in comparison with other combinatorial formats. In general, the interest of policy makers in combinatorial auctions is justified by the laboratory data; when value complementarities are present, package bidding yields improved performance. We find clear differences among the combinatorial auction formats, however, both in terms of efficiency and seller revenue. Notably, the combinatorial clock provides the highest revenue. The FCC's flexible package bidding format performed worse than the alternatives, which is one of the main reasons why it was not implemented.
\end{abstract}

1.Goeree (jacob.goeree@gmail.com): Institute for Empirical Research in Economics, University of Zurich, Blumlisalpstrasse 10, CH-8006,Zurich, Switzerland, and Division of the Humanities and Social Sciences, California Institute of Technology, Mail code 228-77, Pasadena, CA 91125, USA. Brunner (cbrunner01@gmail.com) and Ledyard (jledyard@hss.caltech.edu): Division of the Humanities and Social Sciences, California Institute of Technology, Mail code 228-77, Pasadena, CA 91125, USA. Holt (cah2k@virginia.edu): Department of Economics, University of Virginia, Monroe Hall, McCormick Road, Charlottesville, VA 22903, USA. We acknowledge partial financial support from the Federal Communications Commission (FCC contract 05000012), the Alfred P. Sloan Foundation, the Bankard Fund, and the Dutch National Science Foundation (VICI 453.03.606). The conclusions and recommendations of this paper are those of the authors alone and should not be attributed to the funding organizations. We would like to thank Martha Stancill, Bill Sharkey, and Mark Bykowski for useful discussions. We are grateful to Raj Advani, Charlie Hornberger, Jou McDonnell, Anton Shuster, Walter Yuan, Arzyx, and Eastek Design for programming support, to Lauren Feiler, Joel Grus, Guido Maretto, Alan Miller, Laura Panattoni, Brian Rogers, and David Young for helping run the experiments, and to Dash Optimization for the free academic use of their Xpress-MP software. 
Simultaneous auctions for multiple items are often used when the values of the items are interrelated. An example of such a situation is the sale of spectrum rights by the Federal Communications Commission (FCC). If a telecommunications company is already operating in a certain area, the cost of operating in adjacent areas tends to be lower. In addition, consumers may value larger networks that reduce the cost and inconvenience of "roaming." As a consequence, the value of a collection of spectrum licenses for adjacent areas can be higher than the sum of the values for separate licenses. ${ }^{1}$ Value complementarities arise naturally in many other contexts, e.g. aircraft takeoff and landing slots, pollution emissions allowances for consecutive years, and coordinated advertising time slots. This paper reports a series of laboratory experiments to evaluate alternative methods of running multi-unit auctions, in both high and low-complementarities environments.

Various auction formats have been suggested for selling multiple items with interrelated values. The most widely discussed format is the simultaneous multiple round (SMR) auction, first used by the FCC in 1994. In the SMR auction, bidders are only allowed to bid on single licenses in a series of "rounds," and the auction stops when no new bids are submitted on any license. To win a valuable package of licenses in this type of auction, bidders with value complementarities may have to bid more for some licenses than they are worth individually, which may result in losses when only a subset is won. Avoidance of this "exposure problem" may lead to conservative bidding, lower revenue, and inefficient allocations. ${ }^{2}$

The obvious solution to the exposure problem is to allow bidding for packages of items. In such combinatorial auctions, bidders can make sure they either win the entire package or nothing at all. As a result, bids can reflect value complementarities, which should raise efficiency and seller revenue. Combinatorial bidding, however, may introduce new problems. Consider a situation in which a large bidder submits a package bid for several licenses. If other bidders are interested in buying different subsets of licenses contained in the package, they might find it hard to coordinate their actions, even if the sum of their values is higher than the value of the package to the large bidder (the threshold problem). Thus, there is no clear presumption that package bidding will improve auction performance. The FCC has increasingly relied on laboratory experiments to evaluate the performance of alternative spectrum auctions (see also Jacob $\mathrm{K}$. Goeree and Charles A. Holt, forthcoming). The next section summarizes the main features of the auction formats to be considered.

\footnotetext{
${ }^{1}$ There can also be important synergies in the spectrum frequency dimension, where adjacent bands may improve capacity and reduce interference. For instance, in the FCC auction for air-to-ground communications frequencies in May 2006, a package of three bandwidth units sold for about 4.5 times as much as a single unit, and similar synergies were implied by unsuccessful bids.

${ }^{2}$ In the recent AWS auction (FCC auction 66), for example, the total cost of acquiring $20 \mathrm{MHz}$ of nationwide coverage was $\$ 2.268$ billion for all 734 individual licenses in the "A-block" while the total cost was $\$ 4.174$ billion for the 12 larger regions in the "F-block". Presumably there was a larger exposure problem in the A-block because it consisted a larger number of small licenses.
} 


\section{Alternative Auction Formats}

The various combinatorial auctions to be considered are best understood in terms of how they differ from the incumbent standard, the FCC's simultaneous multi-round auction procedure. Therefore, we will begin by explaining how the SMR auction was implemented in the experiments. Each auction consists of multiple rounds in which bidders have a fixed amount of time to submit their bids. Once the round ends, the highest bid on each license is announced as a provisional winner. Once no more bids are submitted, the auction stops and the provisionally winning bids become the final winning bids.

There are two constraints on bidding. The first constraint is the FCC "activity limit" that determines the maximum number of different licenses for which a bidder can submit bids. Each bidder is assigned a pre-specified activity limit at the beginning of the auction. A bidder's activity limit falls if the number of submitted bids (plus the number of provisionally winning bids in the previous round) is less than the bidder's activity limit in the previous round. Activity is transferable, so a bidder with a limit of 3 could bid on licenses $\mathrm{A}, \mathrm{B}$, and $\mathrm{C}$ in one round and on licenses $\mathrm{E}, \mathrm{F}$, and $\mathrm{G}$ in the next round, for example. The second restriction is that each bid must exceed the previous high bid for that license by a specified bid increment. This requirement is a minimum, and new bids can exceed the "provisionally winning" bid by up to eight bid increments. The only exception to the increment rule is that the provisionally winning bidder is not required to raise that bid. Bidders can observe others' previous bids and can see which of those were provisionally winning. ${ }^{3}$ The effect of activity limits and bid increments is to force bids upward, although there are limited opportunities for withdrawing bids. ${ }^{4}$ The auction stops after a round in which no new bids are submitted and no withdrawals occur.

This multi-round procedure can be adapted to allow for bids on both individual licenses and packages, and this approach has been shown to improve auction performance in some cases. ${ }^{5}$ With package bidding, the relevant price of a license is not necessarily the highest bid on that license; indeed there may not even be a (non-package) bid on a particular license. One approach is to calculate the revenue-maximizing allocation of licenses after each round, and to use "shadow" prices that represent marginal valuations in terms of maximized revenue. Then the price of a package is the sum of the prices for individual items, and new bids in the subsequent round then have to improve on these prices by some minimum increment that depends on the size of the

\footnotetext{
${ }^{3}$ In most FCC auctions to date, bidders' identities are revealed during the auction. More recently, the FCC has contemplated revealing bid amounts but not bidder identities (anonymous or "blind" bidding).

${ }^{4}$ As a partial remedy to the exposure problem, the FCC allows bidders to withdraw their provisionally winning bids in at most two rounds, at a penalty that equals the difference between their withdrawn bids and the subsequent sale price if that is lower. David P. Porter (1999) reports laboratory data showing that the introduction of this withdrawal rule increases the efficiency of the final allocation as well as the seller's revenue.

${ }^{5}$ Stephen J. Rassenti, Vernon L. Smith and Robert L. Bulfin (1982) first used experiments to compare the performance of sealed-bid auctions with and without package bidding. John O. Ledyard, Porter, and Antonio Rangle (1997) provide data comparing several iterative processes. The combinatorial auction produces higher efficiencies in both designs.
} 
package. As with SMR, bidders are given the option of selecting one of a series of prespecified higher increments. This approach, known as RAD (Resource Allocation Design) pricing, is due to Anthony M. Kwasnica, Porter, Ledyard, and Chrstine DeMartini (2005). One advantage of the RAD approach is that prices may convey information about how high a bidder must go to "get into the action" on a particular license or package. ${ }^{6}$ The revenue maximization at the close of each round uses all bids for all completed rounds. This maximization routine results in provisionally winning bids (on licenses or packages) and associated RAD prices. As in the SMR auction, a specified bid increment is added to the RAD price to determine the minimum acceptable bid for the license in the next round. ${ }^{7}$ The minimum acceptable bid for a package is simply the sum of minimum acceptable bids for the licenses it contains. Bidders were allowed to submit multiple bids on licenses and/or packages. The treatment of activity limits is analogous to SMR, with activity being calculated as the number of different licenses being bid for or being provisionally won in the previous round (separately or as part of a package). The auction stops when no new bids are submitted, and the "provisional winning bids" for that round become the final winning bids (withdrawals are not needed with this format).

The FCC developed a variant of RAD pricing, called SMRPB. Of the four formats considered, SMRPB is the only auction procedure that employs an "XOR" bidding rule, which means that each bidder can have at most one winning bid. For example, the XOR rule means that a bidder who is interested in both licenses A and/or B must bid on $\mathrm{A}, \mathrm{B}$, and the package $\mathrm{AB}$, since a bid on $\mathrm{AB}$ alone would preclude winning either license separately while bids on A and B only would preclude winning the package. Since XOR bidding typically calls for making bids on lots of combinations, the activity rule used with the FCC's SMRPB auction is based on the size of the largest package bid, so a bidder with activity 3 could bid on both $\mathrm{ABD}$ and $\mathrm{ABC}$, for example, but not on ABCD. Another difference with RAD concerns the pricing rule: in the SMRPB version, prices adjust slower in response to excess demand because they are "anchored" with respect to prices in the previous round. ${ }^{8}$

An alternative approach to the pricing problem is to have prices rise automatically and incrementally in response to excess demand, via a "clock" mechanism (Porter, Rassenti, Anil Roopnarine, and Smith, 2003). In each round of the combinatorial clock (CC) auction, the price of a combination is the sum of the prices for each component, and bidders can indicate demands for one or more individual items or combinations of items. If more than one bidder is bidding for an item in the current round, either separately or as part of a package, the clock price for that item rises by the bid increment. Otherwise, the price remains the same. There are no provisional winners, but other aspects of this auction are analogous, e.g., activity is defined in terms of the number of different licenses

\footnotetext{
${ }^{6}$ Ideally, the license prices should represent the revenue value of relaxing the constraint that there is only one of each license. The discreteness in license definitions may, however, result in nonexistence of dual prices, and Kwasnica et al. (2005) propose a method of computing approximate prices.

${ }^{7}$ In order to prevent cycles, the bid increment is raised after a round in which revenue does not increase.

${ }^{8}$ See Appendix D in the Goeree and Holt (2005) experiment design report for more details.
} 
for which a bidder indicates a demand. ${ }^{9}$ The auction typically stops when there is no longer any excess demand for any item. ${ }^{10}$ One possible advantage of an incremental clock auction is that it prevents aggressive "jump bids," which have been observed by Kevin McCabe, Rassenti, and Smith (1988) in the laboratory and by R. Preston McAfee and John McMillan (1996) in an FCC auction. ${ }^{11}$ The clock-driven price increments may also alleviate the threshold problem of coordinating small bidders' responses to large package bids. In addition it is possible to add a final round of sealed-bids to the clock phase. This final or shootout phase could be structured as a first-price (pay-as-bid) auction or a second-price auction (proxy bidding, see Lawrence M. Ausubel, Peter Cramton, and Paul Milgrom, 2005).

Results of laboratory experiments suggest that these and other forms of package bidding may enhance performance measures, especially in environments with high complementarities. $^{12,13}$ In the Porter et al. (2003) experiment, for example, the

\footnotetext{
${ }^{9}$ Note that Porter et al. (2003) did not use activity limits in their combinatorial clock auctions.

${ }^{10}$ When there is no more excess demand for any of the licenses but some are in excess supply, the revenue maximizing allocation is calculated using all bids in the current and previous rounds. If this process results in a failure to sell to the remaining bidder for an item, the clock is restarted to let that bidder have another chance to obtain the item. This restart procedure can be illustrated with a simple three-license example, which is taken from the instructions to subjects. Suppose bidder 1 only wants license A and is willing to bid up to 40 for A, bidder 2 only wants license B and is willing to bid up to 40 for B, and bidder 3 only wants license $\mathrm{C}$ and is willing to bid up to 80 for C. Finally, bidder 4 only wants package $\mathrm{ABC}$ and is willing to bid up to 150 for $\mathrm{ABC}$. Initially there is excess demand for all licenses, which causes prices to rise. Bidders 1 and 2 drop out when prices rise to $45,45,45$, but since there is still competition for license $\mathrm{C}$ its price continues to rise. Bidder 4 is willing to keep bidding on $\mathrm{ABC}$ as long as the price of $\mathrm{C}$ does not exceed 60 . So when the price of $C$ rises to 65 , bidder 4 drops out. At prices of $45,45,65$ no one is bidding for licenses $\mathrm{A}$ and $\mathrm{B}$. At this point, bidder 3 is the only one bidding on $\mathrm{C}$ but the computer finds it better to assign $\mathrm{ABC}$ to bidder 4 (for a total of $45+45+60=150$ ) than to assign $\mathrm{A}$ to bidder $1, \mathrm{~B}$ to bidder 2 , and $\mathrm{C}$ to bidder 3 (for a total of $40+40+65=145$ ). To allow bidder 3 (who has a value of 80 for $\mathrm{C}$ ) to get back into the action on license $C$, the computer will raise the price of $C$ further to $70,75, \ldots$ until (i) either bidder 3 drops out or (ii) the revenue from assigning $\mathrm{A}$ to bidder 1, B to bidder 2, and $\mathrm{C}$ to bidder 3 exceeds that of assigning $\mathrm{ABC}$ to bidder 4 . In this manner the price of a license can rise even though only one bidder is still bidding for it. Also, bidders may be assigned a license or package even though they were no longer bidding in the final round (as for bidders 1 and 2 in the example).

${ }^{11}$ In the recent AWS auction, for example, one of the bidders made the maximum allowed jump bid for the hotly contested Northeast and West regional licenses, effectively doubling the prices to about $\$ 1.5$ billion. The main competitors for these licenses ceased bidding immediately afterwards.

12 Jeffrey S. Banks, Ledyard and Porter (1989) proposed a different type of combinatorial auction, called Adaptive User Selection Mechanism (AUSM). In this auction, bidders can submit bids for individual licenses and packages in continuous time. A new bid becomes provisionally winning if revenue can be increased by an allocation that includes the new bid. Kwasnica, Ledyard, Porter and DeMartini (2005) compare RAD and AUSM to SMR in a laboratory setting. Efficiencies observed with RAD and AUSM are similar and higher than those for SMR, but revenue is higher in SMR since many bidders lose money due to the exposure problem. (If we assume that bidders default on bids on which they make losses and thus set the prices of such bids to zero, revenues are in fact higher under AUSM and RAD than under SMR.)

${ }^{13}$ Charles River and Associates also developed a combinatorial auction, called Combinatorial Multi-Round Auction (CMA). In this auction, only bids that are sufficiently high allow bidders to maintain their activity. A bid is sufficiently high when it is at least 5 percent higher than the currently highest combination of bids that spans the same licenses. Banks, Mark Olson, Porter, Rassenti and Smith (2003) ran an experiment to compare the CMA and SMR auction formats. They find that the CMA leads to more efficient allocations but less revenue since many bidders incur losses in their SMR auction experiments due to the exposure
} 
combinatorial clock auction attained 100 percent efficiency in 23 sessions and 99 percent efficiency in two other sessions. Previous experiments have mainly focused on specific auction formats. This paper provides a systematic and parallel consideration of SMR and its most widely discussed alternatives, including the one developed by the FCC. ${ }^{14}$

\section{Experimental Design}

Our design involves groups of eight bidders and 12 licenses, a size that was selected to provide enough added complexity, while still permitting us to obtain sufficient independent observations for a broad range of auction formats and value structures. Bidders' values for the licenses were randomly determined for each auction, which resulted in a rich variety of market structures. There are two types of bidders in this design: small "regional" bidders (labeled 1 through 6) and large "national" bidders (labeled 7 and 8). A graphical representation of bidders' interests is shown in Figure 1. Each diamond represents a different region, and the licenses along the center line $(\mathrm{A}, \mathrm{D}$, E, H, I, and L) are the ones of interest to the two national bidders. In the diamond shaped region on the far left, for example, the regional bidders, 1, 2, 5 and 6, are interested in licenses $\mathrm{B}$ and $\mathrm{C}$, and in addition, each is interested in one of the licenses (A or D) that are targets for the two national bidders. Similarly, in the middle region, small bidders 1 , 2, 3 and 4, are interested in licenses $F$ and $G$, and each one is interested in one of the licenses $(\mathrm{E}$ and $\mathrm{H})$ that are also of interest to the national bidders. The far-right diamond shaped region has a similar structure. Notice that each regional bidder has interests in two adjacent regions, e.g. the left and center diamonds for bidders 1 and 2. Subjects' ID numbers stayed the same throughout the experiment, and, hence, so did their roles as regional or national bidders.

Regional bidders can acquire at most three licenses, and complementarities occur only when licenses in the same region are acquired. For example, if bidder 1 wins the combination $\mathrm{ABE}$, then the value synergies would only apply to $\mathrm{A}$ and $\mathrm{B}$, which are in the same region in Figure 1. Since value synergies do not apply across regions, a group of licenses in one region is a substitute for a group of licenses from another region, which creates an interesting "fitting problem." For example, under the SMR procedure, bidder 1 with an activity of 3 could either bid on licenses $\mathrm{A}, \mathrm{B}$, and $\mathrm{C}$ in the left region or $\mathrm{E}, \mathrm{F}$, and $\mathrm{G}$ in the middle region to capture the regional synergies. Likewise, under the RAD and $\mathrm{CC}$ procedures, bidder 1 could either bid to obtain synergies for the ABC package or the EFG package. The "XOR" rule used in SMRPB facilitates the regional bidders' "choice of region" problem because it allows them to bid on packages from both regions

problem. Porter et al. (2003) also compare CMA to SMR auctions and also find that CMA tends to lead to more efficient allocations.

${ }_{14}$ A common feature of the combinatorial formats discussed in this paper is that they permit "flexible" package bidding, i.e. bidders can construct arbitrary "customized" packages. An alternative approach is to restrict bidding to pre-specified packages as was done in the FCC air-to-ground auction in 2006. Michael H. Rothkopf, Aleksandar Pekeč, and Ronal M. Harstad (1998) have suggested hierarchically structured sets of pre-defined packages to reduce the complexity of the (revenue-based) assignment problem. Goeree and Holt (2008) propose a simple pricing mechanism for hierarchically structured packages and test the resulting auction in the lab. 
knowing that at most one bid can be winning. An additional advantage of the "XOR" rule is that bidders always know the maximum financial liability they face, i.e. the highest dollar amount of any of their bids.

National bidders can acquire up to six licenses and they have value complementarities for all six licenses in some treatments and for only four licenses in other treatments. The larger number of licenses subject to complementarities creates a larger exposure problem for the national bidders. The total number of possible allocations with this setup is $13,080,488$.

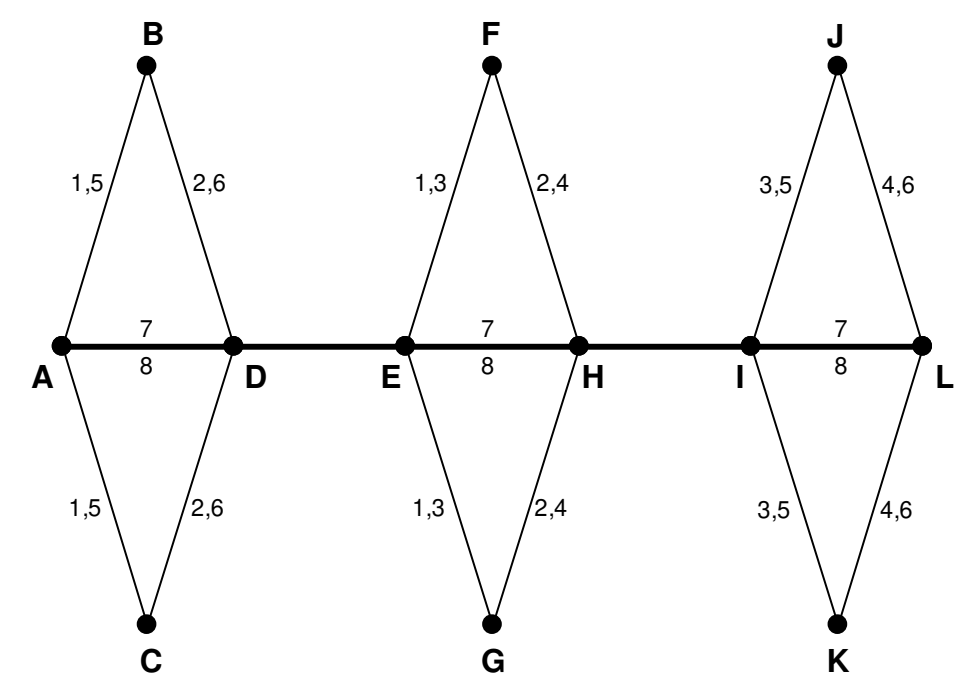

Figure 1: Eight-Bidder Design with Three Regions

Regional bidders (1-6) are interested in one side of one of two diamond-shaped regions. National bidders (7-8) are interested in the middle line connecting all three diamond-shaped regions.

Auction Formats: The four auction formats are described in detail in Appendices A-C. They include three combinatorial formats (SMRPB, RAD, and CC) and one noncombinatorial format (SMR). The main modification of the basic SMR procedures described above is that bid withdrawals were permitted in at most two rounds of an auction. For example, a bidder who withdraws any number of bids in rounds 8 and 10 would not be able to make any withdrawals in subsequent rounds. If a withdrawn bid caused the final sale price to go down, the bidder had to pay the difference. If a license with a withdrawn bid went unsold, however, then the bidder was only responsible for 25 percent of the withdrawn bid, which represents a penalty intended to mimic the effect of having to pay the difference between a withdrawn bid and a lower sale price in a subsequent auction. A key feature of the withdrawal provisions is that the seller (FCC) becomes the provisionally winning bidder at the second highest bid (minus a bid increment), so that the person who originally made the second highest bid would be able to re-enter at that level if the bidder has activity and interest to do so. This provision can benefit a bidder whose interests have changed, perhaps to a different region. 
For each auction format, the experiments cover four different treatments: high/low overlap in national bidders' interests (HO versus LO) and high/low complementarities (HC versus LC). For example, treatment HOHC has high overlap and high complementarities. We next describe the treatment variations in more detail.

Complementarities: Payoffs in the experiment were expressed in terms of "points," where each point was worth $\$ 0.40$ to subjects. (The bid increment was 5 points in all auctions.) The baseline draw distributions are uniform on the range $[5,45]$ for each license of interest to national bidders, and on the range $[5,75]$ for each license of interest to regional bidders. Synergies between licenses are modeled in a linear manner: when a bidder acquires $K$ licenses the value of each goes up by a factor $1+\alpha(K-1)$. In the highcomplementarities treatment, the synergy factor $(\alpha)$ for national bidders was 0.2 . Thus each license acquired by a national bidder goes up in value by 20 percent (with two licenses), by 40 percent (with three licenses), by 60 percent (with four licenses), by 80 percent (with five licenses) and by 100 percent (with all six licenses). With low complementarities, these numbers are 1 percent , 2 percent , 3 percent , 4 percent and 5 percent, corresponding to $\alpha=0.01$. With high complementarities (HC), each license acquired in the same region by a regional bidder goes up in value by 12.5 percent (with two licenses in the same region), and by 25 percent (with three licenses in the same region), so $\alpha=0.125$. With low complementarities, these numbers are 1 percent and 2 percent for regional bidders. These minimal complementarities in the LC treatment allowed us to maintain parallelism in instructions and procedures. Participants were informed about the synergies that applied to regional and national bidders and about the distributions of possible values (but not about others' value draws).

Overlap: With high overlap (HO), each national bidder, 7 and 8 , has value draws from the same distribution for all six licenses on the base of Figure 1, and the complementarities apply equally to all six licenses. In this sense, each national bidder is equally strong across the line. With low overlap (LO), national bidder 7 only receives complementarities for the four licenses on the left side of the base (A, D, E, and H). Conversely, national bidder 8 receives complementarities for the four licenses on the right side (E, H, I, and L). Thus with high complementarities and low overlap, each national bidder has a natural focus of interest that only partially overlaps with the other national bidder's area. One issue of interest is whether this type of partial separation may yield tacit collusion and less aggressive bidding in the center.

Treatment Structure: The two-by-two treatment design yields four treatments for each of the four auction formats, for a total of 16 treatments. We used the same value draws across auction formats so that differences cannot be attributed to specific sequences of value draws. Each session consisted of one or two practice auctions and a series of six auctions for cash payments. The treatment and auction type was unchanged for all auctions in a session, but the randomly generated value draws changed from one auction to the next. In addition, we used new sequences of random draws for each of three "waves" of 16 sessions that spanned all treatments. To summarize, there were 18 (3 waves times 6 auctions) independent sets of value draws that were used in all four auction formats. 
Subjects and Sessions: Before conducting the sessions that form waves 1-3, we trained over 128 Caltech subjects in 16 sessions of eight people. These inexperienced sessions ("wave 0") involved both SMR and combinatorial auctions and were conducted to familiarize subjects with the auction software and bidding environment. ${ }^{15}$ For these inexperienced sessions, we promised to pay each person a $\$ 60$ bonus (in addition to other earnings) if they returned three more times. ${ }^{16}$ This decision to use experienced bidders was based on the complexity of the auction formats and on earlier pilot experiments. For the subsequent data analysis, only the data from waves 1-3 but not from wave 0 is used. In waves 1-3, earnings averaged $\$ 50$ per person per session, including $\$ 10$ show-up fees and bonuses, for sessions that lasted from one and a half to two hours, depending on the number of auctions. ${ }^{17}$ In total, there were 16 training sessions and 48 sessions $(3 \times 16)$ with experienced subjects, each involving a group of eight subjects.

\section{Results}

One way to measure market efficiency is to divide the sum of all bidder values for licenses they won, the actual surplus $\left(S_{\text {actual }}\right)$, by the maximum possible surplus $\left(S_{\text {optimal }}\right)$. It is well known that this simple efficiency measure may be difficult to interpret. For example, adding a constant to all value amounts will tend to raise this efficiency ratio, since efficiency losses are affected by differences in valuations, not absolute levels. A more natural measure of efficiency is calculated on the basis of the difference between the actual surplus and the surplus resulting from a random allocation $\left(S_{\text {random }}\right)$, this being normalized by the maximum such difference.

$$
\text { efficiency }=\frac{S_{\text {actual }}-S_{\text {random }}}{S_{\text {optimal }}-S_{\text {random }}} * 100 \%
$$

The value of a random allocation can be computed by taking the average of the surplus over all possible allocations, of which there are 13,080,488 in total for the design in Figure 1. ${ }^{18}$ This definition of efficiency measures how much the auction raises surplus relative to a random allocation mechanism. In the analysis that follows, we will use these normalized efficiency measures.

Similarly, revenues will be measured as the difference between actual auction revenue and the revenue from a random allocation in which bidders pay their full values

\footnotetext{
${ }^{15}$ The experiments were run using jAuctions, which has been developed at Caltech by Goeree. The jAuctions software consists of a flexible suite of Java-based auction programs designed to handle a wide range of auction formats and bidding environments, including combinatorial auctions with bid-driven or clock-driven prices, private and common valuations, etc. Instructions, which are available on request, were structured around relevant screen shots of the jAuctions program.

${ }_{16}$ As a consequence, most subjects participated in more than one auction format.

${ }^{17}$ In some cases, subjects ended the session with negative earnings, and these subjects were only paid the show-up fee. An alternative would have been to rotate bidder roles during the session, which would have avoided negative final earnings. This is procedure followed in Goeree and Holt (2008).

${ }^{18}$ Without the restriction that regional bidders can acquire at most three licenses, the total number of allocations would simply be $4^{12}=16,777,216$.
} 
for all licenses and packages they receive $\left(R_{\text {random }}=S_{\text {random }}\right)$. This difference is then divided by the difference between the maximum possible revenue $\left(R_{\text {optimal }}=S_{\text {optimal }}\right)$ and the revenue from a random allocation. Note that the optimal revenue benchmark is the revenue obtained if bids equal full value on all licenses and packages leaving zero profits for the bidders, i.e. full rent extraction.

$$
\text { revenue }=\frac{R_{\text {actual }}-R_{\text {random }}}{R_{\text {optimal }}-R_{\text {random }}} * 100 \%
$$

Since $R_{\text {random }}=S_{\text {random }}$ and $R_{\text {optimal }}=S_{\text {optimal }}$, the denominators of the normalized efficiency and revenue measures are equal, and the normalized sum of bidders' profits is simply equal to the difference between efficiency and revenue:

$$
\text { profit }=\frac{S_{\text {actual }}-R_{\text {actual }}}{S_{\text {optimal }}-R_{\text {random }}} * 100 \%=\frac{\sum_{i} \pi_{\text {actual }}^{i}}{S_{\text {optimal }}-S_{\text {random }}} * 100 \%
$$

All efficiency, revenue, and profit measures reported below are normalized in this manner for the specific value sequences used in each auction for each of the three waves of sessions with experienced bidders. ${ }^{19}$

Efficiency: Package bidding is designed to help bidders avoid the "exposure problem" of bidding high for licenses with high complementarities. As expected, switching from SMR to a combinatorial format raises efficiency in the high complementarities treatments. The differences between SMR and the combinatorial formats occur for both of the high complementarities treatments, as can be seen from the left side of Figure 2. In this and subsequent figures the color-coding is as follows: from light to dark the bars correspond to SMR, CC, SMRPB, and RAD respectively.

\footnotetext{
${ }^{19}$ There were occasional glitches in the data recording, i.e. when a bidder's computer would temporarily be offline. A detailed analysis of all the bid books reveals that less than 1 percent of all bids were lost. Since a bidder's activity was determined by the bids she submitted (not according to the bids recorded by the server) this had no adverse effects for the bidder's activity. Unless the round in which this occurred was the final round, the effect of lost bids was negligible.
} 


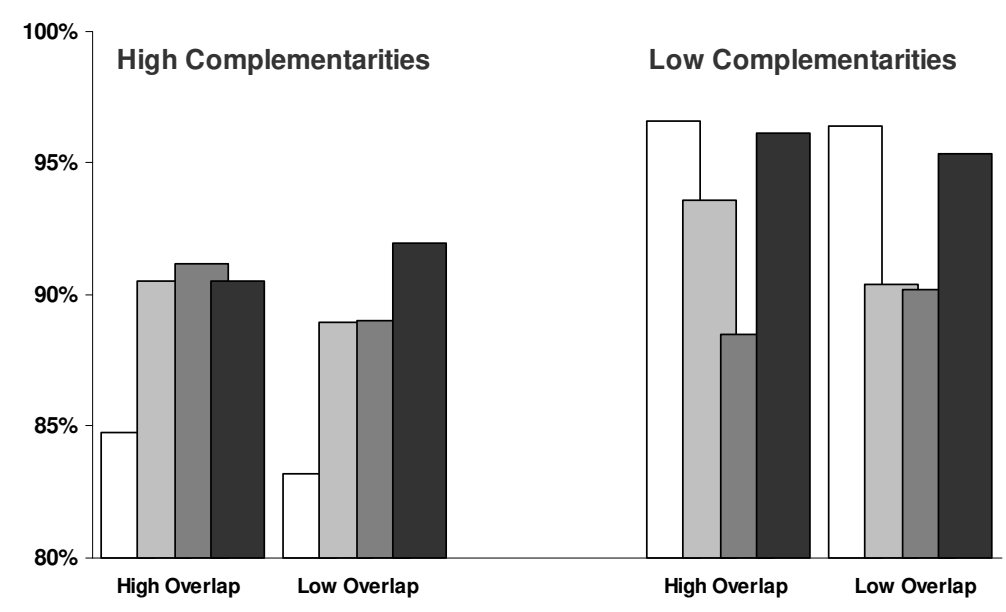

Figure 2: Efficiency by Auction Format

The bars from light to dark (left to right) correspond to SMR, CC, SMRPB and RAD respectively.

In contrast, the switch to combinatorial auctions reduces efficiency when complementarities are minimal (our "low complementarities" treatment). The efficiency levels are now 97 percent for SMR and 89 percent, 92 percent and 96 percent for SMRPB, CC, and RAD respectively. Again, this difference shows up in both LC treatments shown on the right side of Figure 2. Result 1 summarizes our findings, where we use the following notation: $\sim$ implies a pair wise difference is not significant, $\succ^{*}$ indicates significance at the 10 percent level, $\succ^{* *}$ indicates significance at the 5 percent level, and $\succ^{* * *}$ indicates significance at the 1 percent level.

Result 1: With high complementarities, efficiency levels are highest for the three combinatorial formats and are ranked

$$
R A D \sim S M R P B \sim C C \succ^{* *} S M R
$$

With low complementarities, efficiency levels are ranked

$$
R A D \sim S M R \succ^{* *} C C \sim S M R P B
$$

Pooling the low and high complementarities treatments, efficiency levels are ranked

$$
R A D \succ^{*} C C \sim S M R P B \sim S M R
$$

Support: Session averages are grouped by wave and auction format in Appendix D. For example, consider the efficiencies for the $\mathrm{HC}$ treatments (pooling high and low overlap) shown in the eight columns on the left side of Appendix D (top three rows). It is important to compare the auction formats for the same wave, since the valuation draws change from one wave to another. All six of the paired comparisons for the $\mathrm{HC}$ treatments show higher efficiencies for any of the package bidding auctions compared to 
SMR. This effect is significant using a Wilcoxon matched-pairs signed-rank test $(\mathrm{p}=$ 0.03 ). These results are generally reversed with low complementarities, where all paired comparisons between SMR and CC and SMRPB go in the opposite direction (higher efficiency for SMR): this effect is significant $(\mathrm{p}=0.03)$. The only combinatorial auction that is not statistically different from SMR in terms of efficiency is RAD $(\mathrm{p}=0.41)$. When pooling the data from the low and high complementarities treatments, RAD is more efficient than SMRPB $(p=0.02), C C(p=0.09)$, and SMR $(p=0.09)$. There are no significant differences between SMR, SMRPB, and CC.

In addition to being statistically significant, the differences in observed efficiencies are also economically significant. With high complementarities (combining the low and high overlap treatments and data from all three waves), the average efficiency in SMR is 84 percent while it is 90 percent, 90 percent and 91 percent in SMRPB, CC, and RAD respectively.

One reason why SMR leads to low efficiencies with high complementarities is the incidence of unsold licenses, which happens with rates of 4 percent and 7 percent in the high and low overlap treatments respectively, see Appendix D. Unsold licenses typically result from withdrawals late in the auction when a bidder realizes that it will not be possible to obtain the value synergies associated with multiple licenses. After a withdrawal, recall that the seller becomes the provisional winner at the second highest bid, and the person who made that bid previously may have lost activity or interest in that license, which causes it to go unsold. ${ }^{20}$ Withdrawals are not permitted in the combinatorial auctions, where the exposure problem is addressed directly by allowing package bids, so these auctions do not result in unsold licenses. The difference between SMR and any of the combinatorial formats in terms of license sales rates is significant with a Wilcoxon matched-pairs signed-ranks test $(p=0.05)$.

Revenues: Figure 3 shows the revenues by auction format and treatment averaged across sessions (session averages for each parameter/experience wave can be found in rows 4-6 of the table in Appendix D). What is obvious from Figure 3 is that the combinatorial clock auction extracts more rents for the seller in all treatments, even when it is less efficient than other formats.

Result 2: Revenues are highest for the combinatorial clock auction and are ranked

$$
C C \succ^{* * *} R A D \sim S M R P B \sim S M R
$$

\footnotetext{
${ }^{20}$ Since the seller's value for a license is assumed to be 0 , an unsold license was given a value of 0 in the efficiency calculations. This calculation provides a lower bound for the efficiency since unsold licenses are typically sold in later auctions (there is, however, an efficiency loss associated with delays in spectrum use). Alternatively, a rough estimate of the upper bound for the efficiency would be to scale the actual efficiency by $1+x$ where $x$ is the proportion of unsold licenses. By scaling up the efficiencies for the SMR auction in the high-complementarities treatments using an " $x$ factor" of 0.05 (proportion of unsold licenses averaged across treatments) raises average efficiency from 84 percent to 88 percent . This scaled up efficiency is only slightly lower than those for the combinatorial formats, indicating that a large part of the efficiency loss in the SMR auction is due to unsold licenses. Note that these calculations ignore "selection effects," i.e. low-value licenses are more likely to go unsold.
} 
Support: There are three rows in the Revenue section of Appendix D, one for each wave of parameter values. In each row, there are 4 paired comparisons between $\mathrm{CC}$ and a particular alternative format, so overall there are 12 paired comparisons. The CC provides higher revenue in all 12 pair-wise comparisons with each of the alternatives, except for RAD where CC yields higher revenues in 11 of 12 cases. These comparisons are significant using a Wilcoxon matched-pairs signed-rank test $(\mathrm{p}=0.001)$. Basically, $\mathrm{CC}$ is higher than the others with both low and high complementarities $(\mathrm{p}=0.03)$, except for the comparison with RAD in the low-complementarities (LC) treatment $(p=0.06)$. Revenue under RAD is border-line significantly higher than SMRPB when we pool all data $(p=0.109)$. Revenue under RAD is not significantly different from SMR, and SMR and SMRPB raise the same revenues.

These revenue differences are also significant economically: averaging over all treatments and all waves, the revenue from the combinatorial clock format is 50 percent as compared to 37 percent , 40 percent, and 35 percent for the SMR, RAD, and SMRPB auctions respectively.

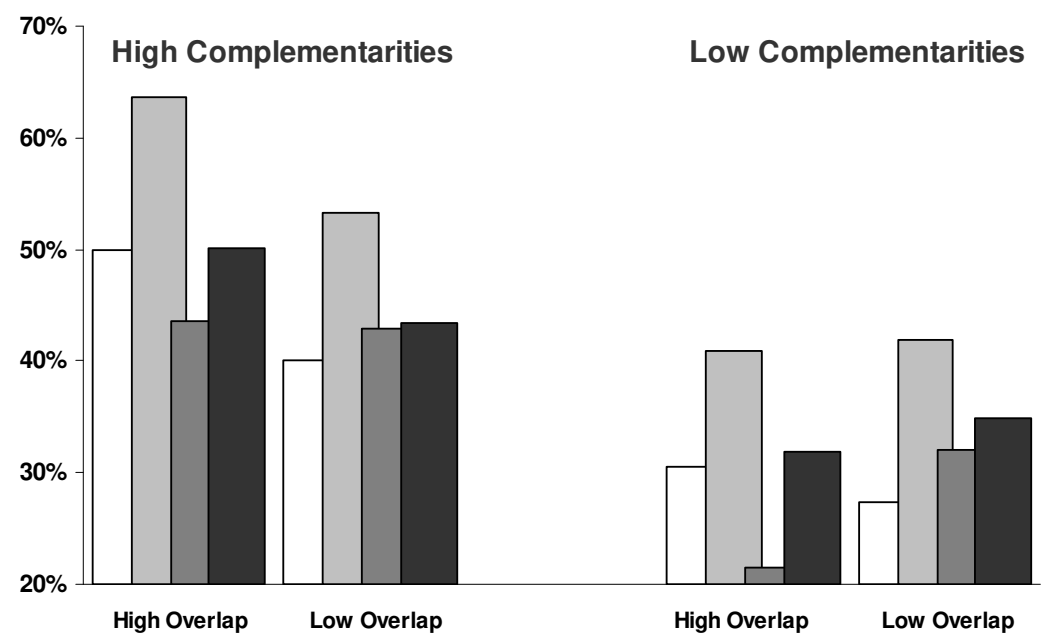

Figure 3: Revenue by Auction Format

The bars from light to dark (left to right) correspond to SMR, CC, SMRPB and RAD respectively.

With high overlap, national bidders own more licenses and, hence, can create bigger packages with higher associated values especially when complementarities are high. The result is that revenues are higher for the High Overlap and High Complementarities bars on the left side of Figure 3. Moreover, national bidders earn more in the high overlap and high complementarities treatments, while the regional bidders do worse (see the table in Appendix D). These revenue and profits results with our prior expectation that there could be more tacit collusion in the low overlap treatments where there is less head-tohead competition between the national bidders.

Profits: Figure 4 shows bidders' profits by auction format and by treatment. The ability to bid for combinations allows bidders to bid high on packages and avoid the exposure 
problem, an effect that is mainly relevant with high complementarities. But if all bidders bid higher, the effect on bidder profits is unclear.

Result 3: Bidders' profits are lowest in the combinatorial clock auction and are ranked

$$
R A D \sim S M R P B \sim S M R \succ^{* * *} C C
$$

Support: Normalized profits are calculated as the differences between entries in the efficiency and revenue rows of Appendix D. With three waves and four treatments, there are 12 paired profit comparisons between $\mathrm{CC}$ and a particular alternative format, and the CC provides lower profits in all 12 pair-wise comparisons with SMR, and for 11 of the 12 comparisons with RAD and SMRPB. These comparisons are significant using a Wilcoxon matched-pairs signed-rank test $(p=0.001)$. Averaged over treatments, profits for $\mathrm{CC}$ are 40 percent while the profits for the other formats are all in a narrow range from 53 percent to 55 percent .

The exposure problem can be alleviated to some extent by the (limited) bid withdrawal provisions built into the SMR bidding rules under consideration. In this manner a bidder may compete aggressively for a package and then decide to withdraw, paying a penalty equal to the difference between the withdrawn bid and the final sale price if it is higher. Withdrawals are more frequent (and the associated penalties higher) with high complementarities, as would be expected. While the possibility of bid withdrawals helps bidders deal with the exposure problem to some extent, some losses did occur when bidders decided not withdraw or had to pay a penalty after a withdrawal. ${ }^{21}$

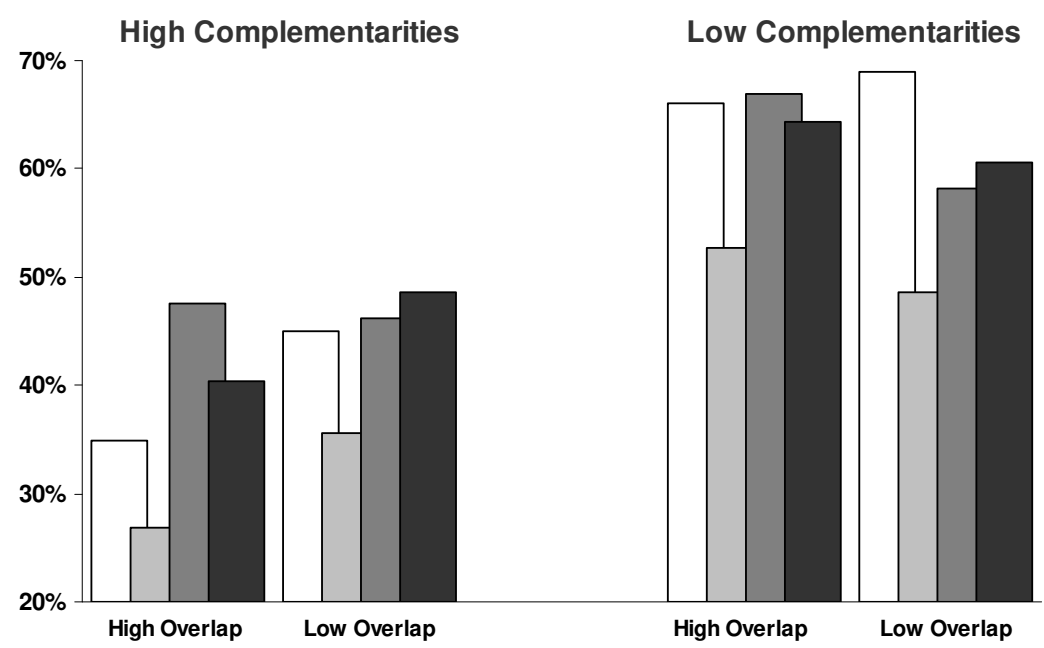

Figure 4: Bidders' Profits by Auction Format

The bars from light to dark (left to right) correspond to SMR, CC, SMRPB and RAD respectively.

${ }^{21}$ National bidders' penalties averaged 2 percent in the HC treatments and were negligible in the LC treatments. Regional bidders' penalties averaged 1 percent in the $\mathrm{HC}$ treatments and were negligible in the LC treatments. 
Summary: Pooling data across treatments and sessions, the revenue and efficiency results by auction format are given in Table 1 . In terms of seller revenues and bidder profits ${ }^{22}$, the combinatorial clock auction is best for the seller and worst for the bidders, but these results are not caused by bidder losses, which are not present in the CC sessions (see the losses rows for Nationals and Regionals in Appendix D). In a comparison with the other formats, the SMRPB auction with XOR bidding is the worst from the seller's point of view (lowest revenue and efficiency), and it is the best from the bidders' point of view (sum of profits for regionals and nationals).

Table 1: Summary Statistics by Auction Format

\begin{tabular}{ccccc}
\hline & SMR & CC & RAD & SMRPB \\
\cline { 2 - 4 } Efficiency & 90.2 percent & 90.8 percent & 93.4 percent & 89.7 percent \\
Revenue & 37.1 percent & 50.2 percent & 40.2 percent & 35.1 percent \\
Profit Regionals & 52.0 percent & 38.5 percent & 50.0 percent & 51.3 percent \\
Profit Nationals & 1.5 percent & 2.3 percent & 3.5 percent & 3.5 percent \\
\hline Profits/Collusive Profits & 34.2 percent & 26.0 percent & 34.1 percent & 34.9 percent \\
\hline
\end{tabular}

The bottom row of Table 1 provides a perspective on the levels of the realized bidders' profits. The percentages in this row are calculated as ratios of actual bidders' profits (national profits plus regional profits) to profits that would result under collusion, i.e. when all bidders drop out at zero price levels resulting in a random allocation with the corresponding surplus, $S_{\text {random }}$, being divided among the bidders. Note that realized profits are far from collusive levels, especially for the combinatorial clock format.

One reason why the SMRPB auction performs the worst in terms of efficiency is that, in the presence of minimal complementarities, the requirement that bidders can only have one bid accepted (the XOR rule) may reduce efficiency, since bidders have to bid on many combinations of licenses to find all possible efficiency gains. (Even though our design, in which regional bidders face a "choice of region" problem, favors the XOR rule.) RAD, in contrast, more or less reduces to SMR with low complementarities while it enables bidders to extract the extra efficiency gains when complementarities are high. Another consideration may be that the inertia in the SMRPB price adjustment algorithm could exaggerate the threshold problem, since attempts to unseat large package bids may have delayed effects due to inertia. The next section explores the treatment differences in greater detail.

\footnotetext{
${ }^{22}$ In Table 1, the "Profit Regionals" row lists the total profit (as a percentage) for the group of 6 regional bidders, while the "Profit Nationals" row lists the combined profits (as a percentage) for the 2 national bidders.
} 


\section{Individual Bidding Behavior}

This section provides an analysis of bidding patterns to explain the main qualitative features of the aggregate data. In particular, with high complementarities, efficiency is significantly lower in SMR than in the three combinatorial auction formats. This suggests that bidders are competing conservatively for larger packages when package bids are not allowed, which could lead to an inefficient allocation.

In order to quantify the effect of "exposure risk" on bidder behavior in SMR, we consider a conditional logit model in which bidders choose among all combinations of licenses that are still feasible given their current activity limits. The conditional logit model includes four variables to explain the choice of a specific bidding basket, see Table 2. Since some sources of noise are individual-specific, we estimate robust standard errors allowing for correlation among observations generated from the same subject.

The "profit" variable is the difference between the value of the basket (the value of the combination of licenses that the bidder is either bidding on or provisionally winning) and the minimum required bid. The value calculations include possible synergies. The coefficient of this "Profit" variable shown in the top row of Table 2 is highly significant; as expected, bidders are more likely to bid on a basket when it yields a higher profit. ${ }^{23}$

The second row of the table shows the effect of the binary variable "PW," which assumes a value of 1 if the bidder is already provisionally winning at least one of the licenses in the basket. The highly negative coefficient indicates that subjects are not likely to raise their bids on licenses they are already provisionally winning, which is again intuitive. The third variable, "Inertia" is a dummy variable that is 1 if the set of licenses that the bidder was provisionally winning or bidding for in the last round is the same as the set of licenses the bidder is bidding for or provisionally winning in the current round.

Finally, "Exposure" is measured as the largest possible loss that a bidder might sustain when bidding on a certain combination of licenses. ${ }^{24}$ We include an interaction term "Exposure * HC" to allow for the possibility that exposure has less of an effect with high complementarities. Note that exposure is significant and negative in both treatments ${ }^{25}$, suggesting that bidders are less likely to bid on baskets that entail the risk of winning licenses at prices above private values. The sign of the coefficient is robust across a variety of different specifications.

\footnotetext{
23 These estimations are based on all bids, including those that could result in negative profits. Such bids are more prevalent in the high-complementarities treatments $(9.2$ percent $)$ than in the lowcomplementarities treatments ( 6.3 percent $)$.

${ }^{24}$ Profit always refers to the difference between value and the minimum required bid for all licenses that the bidder is bidding on or provisionally winning. As noted earlier, we only consider baskets that yield a positive profit. However, when the bidder ends up winning only some of the licenses that he is currently provisionally winning or bidding for, he might sustain a loss.

${ }_{25}$ Running separate regressions for the low and high complementarities treatments yields exposure coefficients of $-0.05(0.007)$ with high complementarities and $-0.11(0.0038)$ with low complementarities.
} 
Table 2: Bidding behavior in SMR

\section{Conditional (fixed-effects) logistic regression}

\begin{tabular}{ccccc} 
N & 184,884 & & Log pseudolikelihood & -6853 \\
Wald chi2(4) & 1642 & & Pseudo R2 & 0.69 \\
Prob $>$ chi2 & 0 & & & \\
\hline Bid & Coef. & Robust Std. Err. & $\mathbf{Z}$ & $\mathbf{P}>|\mathbf{z}|$ \\
\hline Profit & 0.09 & 0.008 & 10.9 & 0 \\
PW & -5.22 & 0.412 & -12.6 & 0 \\
Inertia & 1.44 & 0.081 & 17.7 & 0 \\
Exposure & -0.13 & 0.035 & -3.7 & 0 \\
Exposure ${ }^{*}$ HC & 0.08 & 0.036 & 2.2 & 0.03 \\
\hline
\end{tabular}

To illustrate the importance of exposure, let us consider a simple example for the case of high complementarities. Suppose the national bidder is interested in winning either the national package ADEHIL or nothing at all (and is not the provisional winner on any license). License values are 25 on average so the national package is worth 300 on average. Consider a situation where license prices are 42 each so the minimum required bid would be 47 for each license, totaling 282 for the package. In this case, profit would be 18 but exposure would be 36 , i.e. when the national bidder ends up winning only 3 out of the 6 possible licenses. Hence, the national bidder prefers stop bidding for the national package when its price is 252 (6 times the license price of 42) even though the value of the package is 300 .

The second qualitative feature of the data is that efficiency is higher in RAD than in SMRPB for the minimal complementarities treatment. While activity in RAD is maintained by bidding or provisionally winning a sufficiently large number of different licenses, bidders in SMRPB have to bid on sufficiently large packages to maintain activity. As a result, bidders in RAD can simply bid on single licenses when there are no complementarities. In SMRPB, however, they typically bid on some profitable large package in order to maintain activity and are not also bidding on the subsets of that large package. Therefore, the number of possible allocations in SMRPB tends to be far lower than in RAD. If a bidder has high values for licenses $\mathrm{A}, \mathrm{B}$ and $\mathrm{C}$, for example, that bidder will typically bid on all three licenses separately in RAD. In SMRPB, the same bidder typically bids on package ABC only.

To evaluate why efficiency is lower in SMRPB when complementarities are low, we compare bidding behavior in terms of numbers and sizes of bids. The bidding activity column in Table 3 indicates that with low complementarities, subjects are bidding for or provisionally winning about three different licenses on average in all four formats. However, in SMRPB, bidders do so by bidding on fewer packages of a larger average size than in the other formats. The average number of bids submitted is lower in SMRPB than in any other auction format in every single one of the six sessions with low complementarities. Using a Wilcoxon matched-pairs signed rank test, this difference is 
therefore significant $(\mathrm{p}=0.03, \mathrm{n}=6)$. Similarly, the average size of the bids under SMRPB is higher in all six sessions. This bid size effect is significant in comparisons between SMRPB and any of the other auction formats $(\mathrm{p}=0.03, \mathrm{n}=6)$. The consequence of having fewer bids of larger size is to create a fitting problem under SMRPB. This problem is not present for the other formats where activity can be maintained by submitting many smaller bids.

Table 3: Average Bid Characteristics with Low Complementarities (standard deviation)

\begin{tabular}{cccc}
\hline Auction & Bidding Activity & Number of bids & Size of bids \\
\hline SMRPB & $2.91(0.09)$ & $1.62(0.08)$ & $2.44(0.13)$ \\
SMR & $2.60(0.07)$ & $2.60(0.07)$ & $1.00(0.00)$ \\
RAD & $2.69(0.09)$ & $2.11(0.28)$ & $1.60(0.24)$ \\
CC & $2.66(0.07)$ & $3.15(0.52)$ & $1.69(0.13)$ \\
\hline
\end{tabular}

The seller's revenue is higher in the combinatorial clock auction than in any other auction format in all treatments of our experiment. In SMR, efficiency and thus also revenue is negatively affected by the exposure problem when complementarities are high. Moreover, the option to withdraw bids leads to a higher fraction of unsold licenses in SMR, which further reduces the seller's revenue.

In RAD and SMRPB, the threshold problem can potentially reduce the seller's revenue, since large bidders may be able to win packages at low prices when small bidders are unable to coordinate their actions. In order to test for the effects of the threshold problem in SMRPB and RAD, we look at whether small bidders bid up to their values in periods in which they end up winning nothing. Since the threshold problem only pertains to small bids, we only look at bids on individual licenses and packages containing two licenses.

Recall that the combinatorial clock auction solves the threshold problem by forcing bidders to increase bids together on licenses for which there is excess demand. On average, small losing bids are closer to bidders' values in the combinatorial clock auction than in either RAD or SMRPB ( $\mathrm{p}<0.001$ for both comparisons using a Wilcoxon matched-pairs signed rank test with 12 observations). The differences between RAD and SMRPB are not significant $(\mathrm{p}=0.23, \mathrm{n}=12)$, see also Table 4 .

Table 4: Bidding up to value

\begin{tabular}{ccc}
\hline auction & Mean & standard deviation \\
\hline CC & 99.2 percent & 9.9 percent \\
SMRPB & 87.1 percent & 5.3 percent \\
RAD & 85.8 percent & 3.0 percent \\
\hline
\end{tabular}


If the threshold problem is indeed the reason why small bidders fail to bid up to their values, one would expect large bidders in SMRPB and RAD to submit aggressive "jump bids," i.e. to bid more than the minimum required bid in the early rounds of the auction. Taking the average across all bids submitted during the first five rounds, the difference between the bid price and the minimum required bid is higher in SMRPB than in RAD both with high and low complementarities, see Table 5. However, these differences are not significant (pooling data from low and high complementarities yields $\mathrm{p}=0.15$ using a Wilcoxon matched-pairs signed rank test with 12 observations). Since the combinatorial clock auction does not allow jump bids, both these differences are higher for RAD and SMRPB than for CC (see Table 5).

Table 5: Size of jumpbid (bid - minimum required bid)

\begin{tabular}{cccc}
\hline Auction & Treatment & Mean & Standard Deviation \\
\hline CC & all & 0 & 0 \\
RAD & HC & 3.1 & 2.2 \\
RAD & LC & 1.3 & 0.8 \\
SMRPB & HC & 4.1 & 2.1 \\
SMRPB & LC & 2.6 & 1.2 \\
\hline
\end{tabular}

\section{Conclusions}

The simultaneous multi-round auction is considered to be a remarkably successful application of game theory, with careful attention to the details of implementation by policy makers. This auction format is currently used around the world, and government officials in other agencies now routinely consult the FCC on auction design matters. Concerns about the effects of value complementarities have convinced many people that new procedures need to be developed and tested. In particular, the FCC developed a package bidding variant of the SMR auction, known as SMRPB. This paper compares the performance of these two alternatives and that of two other package-bidding formats: the combinatorial clock (Porter et al., 2003) and the RAD auction (Kwasnica et al., 2005).

The experiments were conducted with a common jAuctions bidder interface and parallel sets of value draws, for an array of structural and auction format treatments. The combinatorial auction procedures used (RAD, SMRPB, and CC) all result in higher efficiency than the currently used SMR procedure when value complementarities are present. It is important to emphasize that value complementarities are not just a theoretical possibility; a package of three bandwidth segments sold for about five times as much as a single segment in a recent FCC auction that offered a very limited menu of pre-specified package bidding options. Complementarities are almost surely significant for other potential applications of package bidding such as emissions permits for successive years. 
However, of the three combinatorial auction types, SMRPB performed worst in terms of revenue and efficiency. One distinguishing feature of SMRPB is the XOR rule, which allows each bidder to have at most a single winning bid. A bidder who is interested in obtaining one or more licenses in a certain region thus has to bid on all possible combinations of those licenses. In the experiment, however, bidders submit only a few bids per round in which case the additional constraint of at-most-one-winning bid per bidder becomes detrimental for efficiency and revenue. The poor performance of SMRPB reported here was a main factor in the FCC's decision not to implement it.

The FCC subsequently decided to implement package bidding for one of the five blocks in the recently conducted $700 \mathrm{MHz}$ auction. Unlike the fully flexible package bidding formats considered in this paper, the FCC opted to use a simple format with a single 50-state package and two additional packages (Atlantic and Pacific). This setup is a simple version of the Hierarchical Package Bidding mechanism proposed by Goeree and Holt (forthcoming). Under this mechanism, predefined packages are structured in a hierarchical manner and after each round of bidding, prices for all licenses and packages are determined such that they signal the bid amounts required to unseat the current provisional winners.

Without extensive knowledge of bidders' valuations, there will be some efficiency loss associated with using predefined packages. However, the simplicity of the hierarchical package structure (e.g. individual licenses, non-overlapping regional packages, and a single nationwide package) avoids fitting problems that can arise with fully flexible package bidding. For example, if a nationwide package bid is winning then the non-overlapping nature of the regional packages together with the simple pricing feedback allows regional bidders to avoid the threshold problem. This approach was tested using laboratory experiments based on two-layer and three-layer hierarchies and the results were cited by the FCC as a factor in their decision to use Hierarchical Package Bidding in the recent $700 \mathrm{MHz}$ auction. 


\section{References}

Ausubel, Lawarence M., Peter Cramton and Paul Milgrom. 2005. "The Clock-Proxy Auction: A Practical Combinatorial Design," in Combinatorial Auctions, Eds. P. Cramton, R. Steinberg and Y. Shoham, MIT Press.

Banks, Jeffrey S., John O. Ledyard, and David P. Porter. 1989. “Allocating Uncertain and Unresponsive Resources: An Experimental Approach," Rand Journal of Economics, 20(1): 1-25.

Banks, Jeffrey S., Mark Olson, David P. Porter, Stephen J. Rassenti, and Vernon L. Smith. 2003. "Theory, Experiment and the Federal Communications Commission Spectrum Auctions," Journal of Economic Behavior and Organization, 51: 303350.

Goeree, Jacob K. and Charles A. Holt. 2005. "Comparing the FCC's Combinatorial and Non-Combinatorial Simultaneous Multi-Round Auctions: Experimental Design Report," Report prepared for the Wireless Communications Bureau of the Federal Communications Commission.

Goeree, Jacob K., Charles A. Holt, and John O. Ledyard. 2006. "An Experimental Comparison of the FCC's Combinatorial and Non-Combinatorial Simultaneous Multiple Round Auctions," Report prepared for the Wireless Communications Bureau of the Federal Communications Commission.

Goeree, Jacob K. and Charles A. Holt. Forthcoming. "Hierarchical Package Bidding: A 'Paper \& Pencil' Combinatorial Auction," Games and Economic Behavior.

Kwasnica, Anthony M., John O. Ledyard, David P. Porter, and Christine DeMartini. 2005. "A New and Improved Design for Multi-Object Iterative Auctions," Management Science, 51(3): 419-434.

Ledyard, John O., David P. Porter, and Antonio Rangel. 1997. "Experiments Testing Multiobject Allocation Mechanisms," Journal of Economics and Management Strategy, 6(3): 639-675.

McAfee, Preston R. and John McMillan. 1996. "Analyzing the Airwaves Auction," Journal of Economic Perspectives, 10(1): 159-175.

McCabe, Kevin, Stephen J. Rassenti, and Vernon L. Smith. 1989. "Designing 'Smart' Computer Assisted Markets," European Journal of Political Economy, 5: 259283.

Porter, David P. 1999. "The Effect of Bid Withdrawal in a Multi-Object Auction," Review of Economic Design, 4(1): 73-97.

Porter, David P., Stephen J. Rassenti, Anil Roopnarine and Vernon L. Smith. 2003. "Combinatorial Auction Design," Proceedings of the National Academy of Sciences, 100(19): 11153-11157.

Rassenti, Stephen J., Vernon L. Smith, and Robert L. Bulfin. 1982. "A Combinatorial Auction Mechanism for Airport Time Slot Allocation," Bell Journal of Economics, 13: 402-417.

Rothkopf, Michael H., Aleksandar Pekeč and Ronal M. Harstad. 1998. "Computationally Manageable Combinational Auctions," Management Science, 44: 1131-1147. 


\section{Appendix A: Rules for the SMR Laboratory Auctions}

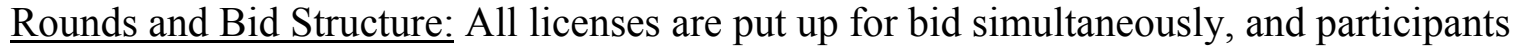
may only submit bids on individual licenses. The auction consists of successive rounds in which participants may place bids. Following each round, the high bid for each license is posted. These high bids then become the standing bids for the subsequent round.

Acceptable Bids: In the first round, an acceptable bid must be equal to or exceed the initial price of 0 by 5 points (each point equaled 40 cents in the experiment). Subsequently, in order to be acceptable, a bid must exceed the provisionally winning bid for the license by at least 5 points. Bidders are given the choice of making one of eight incrementally higher bids (in 5 point increments).

Bid Withdrawal: Each bidder has at most 2 rounds in which they are permitted to withdraw any of their provisionally winning bids. After the withdrawal, the seller becomes the provisionally winning bidder for the withdrawn license and the minimum acceptable bid in the following round equals the second highest bid received on the license, which may be less than or equal to (in the case of tied bids) the amount of the withdrawn bid. A withdrawing bidder pays a penalty equal to the maximum of zero or the difference between the price at which the bidder withdrew its bid and the final sale price in the current auction. If the license goes unsold, the bidder would normally be responsible for paying the difference between the withdrawn bid and the sale price in a subsequent auction, plus a small percentage penalty of 3 percent . In the experiment, there is no subsequent auction, so these penalties for the case of an unsold license were implemented by requiring that the bidder pay a penalty of 25 percent of the withdrawn bid.

Bidding Eligibility and Activity: Each license in the experiment is assigned one bidding unit. The total number of bidding units available to the bidder establishes the bidder's maximum "eligibility" to bid. National bidders begin each auction with 6 activity units and regional bidders begin with 3 . In each round, a bidder's activity is calculated as the number of licenses for which that bidder is a provisional winner, plus the number of licenses for which acceptable bids are submitted. If a bidder's activity falls below the bidder's current activity limit, that limit is reduced to equal the bidder's actual activity. There were no activity rule wavers in the experiment, so a reduction in activity would put an upper limit on the bidder's activity for all subsequent rounds of that auction.

End of Round Feedback: At the end of each round, bidders receive information on all provisionally winning bids, withdrawn bids, and the corresponding bidder ID numbers. Bidders also see the sum of their own values for the licenses that they are provisionally winning and prices that would be paid for the licenses if the auction had ended.

Closing Rule: The auction closes after any round in which no new bids were placed and no bids were withdrawn. In this case provisionally winning bids become winning bids that are used to calculate auction earnings. The experiment did not allow for defaults on payments, so gains were added to cumulative earnings and losses were subtracted. 


\section{Appendix B: Rules for RAD (in Bold) and SMRPB (in Italics)}

Rounds and Bid Structure: This is a simultaneous, multi-round auction in which participants may submit one or more bids on individual licenses or on combinations of licenses (packages). Provisionally winning bids are calculated by maximizing seller revenue for the round, using all current and past bids. (SMRPB: Bids have an exclusive "XOR" structure in the sense that each bidder can have at most one provisionally winning bid.)

Acceptable Bids: In the first round, an acceptable bid must be equal to or exceed the minimum opening bid of 0 by 5 points for each license, or by 5 points times the number of licenses in a package. After each subsequent round, "prices" are calculated for each license on the basis of bids received in the previous round. The pricing rule, as specified in Appendix D of the Experiment Design Report, calculates prices that reflect (as closely as possible) the marginal sales revenue of each license based on bids received. Prices for packages are the given by the sum of the prices for each license in the package. In order to be acceptable, a bid must exceed the price of a license or package at least 5 points times the number of licenses covered by the bid. Bidders are given the choice of making one of eight incrementally higher bids (in 5 point increments).

Bidding Eligibility and Activity: Each license in the experiment is assigned one bidding unit. The total number of bidding units available to the bidder establishes the bidder's maximum "eligibility" to bid ( 3 for regional bidders and 6 for national bidders). (RAD:

In each round, a bidder's activity is calculated as the number of different licenses for which that bidder is a provisional winner or for which that bidder places a bid, either singly or as part of a package.) (SMRPB: In each round, a bidder's activity is calculated as the maximum of (1) the size of the largest package the bidder is provisionally winning and (2) the size of the largest package the bidder is bidding for.) If a bidder's activity falls below the bidder's current activity limit, that limit is reduced to equal the bidder's actual activity. There were no activity rule wavers in the experiment, so a reduction in activity would put an upper limit on the bidder's activity for all subsequent rounds of that auction.

End of Round Feedback: At the end of each round, bidders receive information on all provisionally winning bids (for licenses and packages) and the corresponding bidder ID numbers. Bidders also see the prices for all licenses, the sum of their own values for the licenses and packages that they are provisionally winning, and the sum of prices that would be paid for those licenses and packages if the auction had ended.

Closing Rule: The auction closes after any round in which no new bids were placed. In this case provisionally winning bids become winning bids that are used to calculate auction earnings. The experiment did not allow for defaults on payments, so gains were added to cumulative earnings and losses were subtracted. 


\section{Appendix C: Rules for the Combinatorial Clock (CC)}

Rounds and Bid Structure: This is a simultaneous, multi-round auction in which participants may submit one or more bids on individual licenses or on combinations of licenses (packages). Submitted bids stay active until they are removed (just as provisionally winning bids in the other formats are automatically renewed).

Acceptable Bids: In the first round, an acceptable bid must be equal to or exceed the minimum opening bid of 0 by 5 points for each license, or by 5 points times the number of licenses in a package. After each subsequent round, "prices" are calculated for each license on the basis of bids received in the previous round. If a license is in the contained in a bid made by more than one bidder (individually or as part of a package), then the price for that license will rise by the bid increment (5), otherwise the price does not change. For example, if one bidder is bidding on $\mathrm{A}$ and $\mathrm{AB}$, and if the only other bidder is bidding on $\mathrm{B}$, then the price of $\mathrm{B}$ will increase and the price of $\mathrm{A}$ will stay unchanged. Prices for packages are the given by the sum of the prices for each license in the package, so the price of a package can increase by at most the product of the bid increment and the number of licenses in the package.

Bidding Eligibility and Activity: Each license in the experiment is assigned one bidding unit. The total number of bidding units available to the bidder establishes the bidder's maximum "eligibility" to bid ( 3 for regional bidders and 6 for national bidders). In each round, a bidder's activity is calculated as the number of different licenses for which that bidder places a bid, either singly or as part of a package. For example, a regional bidder with an initial activity limit of 3 would be able to bid on packages $\mathrm{BC}$ and on $\mathrm{ABC}$, but not on $\mathrm{ABC}$ and $\mathrm{E}$. If a bidder's activity falls below the bidder's current activity limit, that limit is reduced to equal the bidder's actual activity. There were no activity rule wavers in the experiment, so a reduction in activity would put an upper limit on the bidder's activity for all subsequent rounds of that auction.

End of Round Feedback: At the end of each round, bidders receive information on all prices and submitted bids (for licenses and packages), with the corresponding bidder ID numbers.

Closing Rule: The auction generally closes after any round in which there is no excess demand, i.e. no license is in the "bidding basket" of more than one person. However, if there is excess supply at this point (one or more unclaimed licenses), then a revenue maximization routine is run using all submitted bids in all rounds in order to arrange the sale of all licenses. If the resulting allocation displaces the sole remaining bidder for any of the licenses, the auction is restarted and the clock prices on those licenses are raised to let those bidders have the chance to reclaim them. 
Appendix D: Efficiency, Revenue, and Profits by Auction Format

\begin{tabular}{|c|c|c|c|c|c|c|c|c|c|c|c|c|c|c|c|c|}
\hline & \multicolumn{4}{|c|}{ HOHC } & \multicolumn{4}{|c|}{ LOHC } & \multicolumn{4}{|c|}{ HOLC } & \multicolumn{4}{|c|}{ LOLC } \\
\hline & SMR & $\mathrm{CC}$ & RAD & SMRPB & SMR & $\mathrm{CC}$ & RAD & SMRPB & SMR & CC & RAD & SMRPB & SMR & CC & RAD & SMRPB \\
\hline \multicolumn{17}{|l|}{ Efficiency } \\
\hline Wave 1 & $86 \%$ & $92 \%$ & $89 \%$ & $88 \%$ & $86 \%$ & $89 \%$ & $93 \%$ & $89 \%$ & $96 \%$ & $92 \%$ & $95 \%$ & $88 \%$ & $96 \%$ & $82 \%$ & $94 \%$ & $93 \%$ \\
\hline Wave 2 & $85 \%$ & $94 \%$ & $89 \%$ & $93 \%$ & $79 \%$ & $91 \%$ & $89 \%$ & $91 \%$ & $96 \%$ & $93 \%$ & $95 \%$ & $84 \%$ & $97 \%$ & $93 \%$ & $93 \%$ & $86 \%$ \\
\hline Wave 3 & $84 \%$ & $86 \%$ & $94 \%$ & $93 \%$ & $85 \%$ & $87 \%$ & $94 \%$ & $87 \%$ & $98 \%$ & $96 \%$ & $98 \%$ & $93 \%$ & $96 \%$ & $96 \%$ & $99 \%$ & $92 \%$ \\
\hline Average & $85 \%$ & $91 \%$ & $90 \%$ & $91 \%$ & $83 \%$ & $89 \%$ & $92 \%$ & $89 \%$ & $97 \%$ & $94 \%$ & $96 \%$ & $88 \%$ & $96 \%$ & $90 \%$ & $95 \%$ & $90 \%$ \\
\hline \multicolumn{17}{|l|}{ Revenue } \\
\hline Wave 1 & $54 \%$ & $70 \%$ & $56 \%$ & $46 \%$ & $40 \%$ & $59 \%$ & $50 \%$ & $49 \%$ & $30 \%$ & $46 \%$ & $40 \%$ & $21 \%$ & $30 \%$ & $47 \%$ & $29 \%$ & $38 \%$ \\
\hline Wave 2 & $55 \%$ & $71 \%$ & $52 \%$ & $44 \%$ & $42 \%$ & $56 \%$ & $38 \%$ & $48 \%$ & $32 \%$ & $42 \%$ & $33 \%$ & $15 \%$ & $28 \%$ & $40 \%$ & $41 \%$ & $36 \%$ \\
\hline Wave 3 & $42 \%$ & $51 \%$ & $43 \%$ & $41 \%$ & $38 \%$ & $45 \%$ & $42 \%$ & $33 \%$ & $30 \%$ & $35 \%$ & $23 \%$ & $28 \%$ & $24 \%$ & $39 \%$ & $34 \%$ & $23 \%$ \\
\hline Average & $50 \%$ & $64 \%$ & $50 \%$ & $44 \%$ & $40 \%$ & $53 \%$ & $43 \%$ & $43 \%$ & $31 \%$ & $41 \%$ & $32 \%$ & $21 \%$ & $27 \%$ & $42 \%$ & $35 \%$ & $32 \%$ \\
\hline \multicolumn{17}{|l|}{ Profit Nationals } \\
\hline Wave 1 & $3 \%$ & $3 \%$ & $10 \%$ & $10 \%$ & $4 \%$ & $1 \%$ & $1 \%$ & $-3 \%$ & $4 \%$ & $2 \%$ & $-3 \%$ & $5 \%$ & $3 \%$ & $2 \%$ & $0 \%$ & $2 \%$ \\
\hline Wave 2 & $-4 \%$ & $3 \%$ & $6 \%$ & $7 \%$ & $-2 \%$ & $3 \%$ & $4 \%$ & $2 \%$ & $4 \%$ & $2 \%$ & $3 \%$ & $1 \%$ & $2 \%$ & $1 \%$ & $4 \%$ & $4 \%$ \\
\hline Wave 3 & $1 \%$ & $5 \%$ & $9 \%$ & $6 \%$ & $1 \%$ & $2 \%$ & $1 \%$ & $2 \%$ & $3 \%$ & $0 \%$ & $3 \%$ & $4 \%$ & $1 \%$ & $1 \%$ & $4 \%$ & $2 \%$ \\
\hline Average & $0 \%$ & $4 \%$ & $8 \%$ & $8 \%$ & $1 \%$ & $2 \%$ & $2 \%$ & $0 \%$ & $3 \%$ & $2 \%$ & $1 \%$ & $3 \%$ & $2 \%$ & $1 \%$ & $3 \%$ & $3 \%$ \\
\hline Losses & $2 \%$ & $0 \%$ & $0 \%$ & $0 \%$ & $0 \%$ & $0 \%$ & $0 \%$ & $2 \%$ & $0 \%$ & $0 \%$ & $1 \%$ & $0 \%$ & $0 \%$ & $0 \%$ & $0 \%$ & $0 \%$ \\
\hline \multicolumn{17}{|l|}{ Profit Regionals } \\
\hline Wave 1 & $29 \%$ & $19 \%$ & $23 \%$ & $32 \%$ & $48 \%$ & $29 \%$ & $41 \%$ & $43 \%$ & $62 \%$ & $44 \%$ & $58 \%$ & $63 \%$ & $63 \%$ & $32 \%$ & $64 \%$ & $53 \%$ \\
\hline Wave 2 & $33 \%$ & $19 \%$ & $31 \%$ & $42 \%$ & $38 \%$ & $32 \%$ & $47 \%$ & $42 \%$ & $60 \%$ & $49 \%$ & $59 \%$ & $68 \%$ & $66 \%$ & $52 \%$ & $48 \%$ & $46 \%$ \\
\hline Wave 3 & $41 \%$ & $31 \%$ & $41 \%$ & $46 \%$ & $46 \%$ & $40 \%$ & $51 \%$ & $52 \%$ & $65 \%$ & $60 \%$ & $72 \%$ & $60 \%$ & $71 \%$ & $56 \%$ & $61 \%$ & $67 \%$ \\
\hline Average & $34 \%$ & $23 \%$ & $32 \%$ & $40 \%$ & $44 \%$ & $33 \%$ & $47 \%$ & $46 \%$ & $63 \%$ & $51 \%$ & $63 \%$ & $64 \%$ & $67 \%$ & $47 \%$ & $58 \%$ & $55 \%$ \\
\hline Losses & $0 \%$ & $0 \%$ & $0 \%$ & $0 \%$ & $0 \%$ & $0 \%$ & $1 \%$ & $0 \%$ & $0 \%$ & $0 \%$ & $0 \%$ & $0 \%$ & $0 \%$ & $1 \%$ & $1 \%$ & $1 \%$ \\
\hline \# Rounds & 15.2 & 22.8 & 24.2 & 17.1 & 16.3 & 22.8 & 22.2 & 18.7 & 13.7 & 18.1 & 16.4 & 17.9 & 14.9 & 18.8 & 15.8 & 21.8 \\
\hline Unsold Licenses & $4 \%$ & $1 \%$ & $0 \%$ & $0 \%$ & $7 \%$ & $0 \%$ & $0 \%$ & $0 \%$ & $0 \%$ & $1 \%$ & $0 \%$ & $0 \%$ & $0 \%$ & $0 \%$ & $0 \%$ & $0 \%$ \\
\hline
\end{tabular}

